\title{
LA REORGANIZACIÓN DEL TERRITORIO PARROQUIAL DE LA ARQUIDIÓCESIS DE MÉXICO DURANTE LA PRELACÍA DE MANUEL RUBIO Y SALINAS (1749-1765)
}

\author{
POR \\ María Teresa Álvarez ICAZA LONGORIA \\ Universidad Nacional Autónoma de México
}

\begin{abstract}
RESUMEN
A partir de 1750 el arzobispo Manuel Rubio y Salinas ordenó que se llevara a cabo la transferencia a clérigos de doctrinas hasta entonces administradas por el clero regular. Varios de los curatos secularizados tenían un territorio muy amplio; el prelado diocesano tomó la decisión de dividirlos. Al existir más parroquias tenían ocasión de conseguir acomodo mayor número de clérigos; además, argumentaba Rubio, los feligreses se veían beneficiados porque mejoraba su administración espiritual. El establecimiento de estas demarcaciones a veces fue realizado con el consenso de los diversos actores involucrados, pero en otras implicó conflictos que pudieron representar obstáculos importantes en el proceso de creación de nuevas sedes parroquiales.
\end{abstract}

PAlABRAS ClAVE: Arzobispado de México, Manuel Rubio y Salinas, secularización, división parroquial, nuevos curatos.

\section{THE REORGANIZATION OF THE PAROCHIAL TERRITORY OF THE ARCHDIOCESE OF MEXICO DURING MANUEL RUBIO'S GOVERNMENT (1749-1765)}

\begin{abstract}
Since 1750 Archbishop Manuel Rubio y Salinas ordered the taking place of the transference to clerics from doctrines previously administered by the regular clergy. Several of the secularized curates used to have a vast territory, the Diocesan prelate decided to divide them. As there were more parishes, a higher
\end{abstract}


number of the clerics could have more chance to get accommodation. In addition, argued Rubio, the parishioners were favored because it improved their spiritual administration. The establishment of these boundaries was sometimes done with the consensus of several actors involved, but in other cases it involved conflicts that could represent a number of major obstacles in the process of creating new parishes.

KEY WORDS: Archbishop of México, Manuel Rubio y Salinas, secularization, parish división, new, parishes.

Recibido/Received 02/01/2011

Aceptado/Accepted 15/03/2011

\section{LOS PREPARATIVOS}

Los reajustes jurisdiccionales en el arzobispado de México ocurrieron desde etapas tempranas. En el territorio de esta demarcación se establecieron primeramente las distintas órdenes mendicantes; los religiosos se asentaban en las cabeceras para atender desde allí a los pueblos de visita. Fue común que la competencia entre las órdenes y de los regulares con los seculares se diera en los pueblos sujetos; esto se conjugaba con el deseo de autonomía de los vecinos de los pueblos menores.

Algunos sujetos pudieron alcanzar el status de cabecera, para lo cual se tomaron en consideración diversos criterios: tamaño de población, situación geográfica, fechas de fundación, mercados y otros. ${ }^{1}$ Como en las cabeceras residía el cura, un requisito indispensable era la existencia de una iglesia digna y convenientemente provista. ${ }^{2} \mathrm{Al}$ paso del tiempo las jurisdicciones políticas y eclesiásticas se modificaron constantemente.

En el siglo XVIII el arzobispado de México ocupaba una ancha franja del área central de la Nueva España; iba de la costa del Atlántico a la del Pacífico; abarcaba desde Tampico en el noreste hasta Acapulco en el suroeste. ${ }^{3}$ En este vasto territorio había zonas urbanas de gran concentración demográfica, en especial la capital del virreinato, pero también había un vasto espacio rural ocupado por pueblos, ranchos y haciendas. Hacia 1746, según los datos

\footnotetext{
${ }^{1}$ Charles GiBson, Los aztecas bajo el dominio español, México, 2003, 58.

${ }^{2}$ Lockhart aborda a detalle el tema de la fragmentación del altépetl y el peso del factor religioso en el proceso. James LOCKHART, Los nahuas después de la conquista, México, 1999, 299.

${ }^{3}$ William Taylor señala que el arzobispado de México comprendía la parte más al norte del actual estado de Veracruz, el oriente de San Luis Potosí, el nororiente de Guanajuato, el oriente y suroeste de Querétaro, todo Hidalgo, el Estado de México, el Distrito Federal y Morelos, así como buena parte de Guerrero. William TAYLOR, Ministros de lo sagrado, vol I, México, 1999, 55. 
consignados por José Antonio Villaseñor, existían en la arquidiócesis mexicana 192 curatos, 104 de ellos eran administrados por el clero regular y 88 por clérigos seculares. ${ }^{4}$

Durante la gestión de Manuel Rubio y Salinas al frente del arzobispado de México se aceleró el ritmo en la creación de nuevos curatos. Esto se relaciona directamente con el proceso de secularización de doctrinas que este prelado llevó a cabo. Rubio había participado en la junta que había decidido la transferencia de curatos de los regulares a los seculares. Poco tiempo después de su llegada a la ciudad de México fue emitida la orden que dio inicio al programa.

El texto de esta real cédula, fechada el 4 de octubre de 1749, señalaba que a los regulares se les habían encargado los curatos «precariamente». Las instancias eclesiásticas a través de las cuales los frailes daban atención espiritual a la población indígena tenían un nombre que daba idea de su carácter temporal: eran llamadas doctrinas. Cuando el adoctrinamiento de los indios se completara debían pasar a ser administrados por el clero secular. ${ }^{5}$

Fernando VI afirmaba que por derecho a los curas diocesanos les correspondía hacerse cargo de la atención espiritual de los feligreses. Como había llegado el momento de contar «con competente número de clérigos seculares de identidad y suficiencia» debía proceder la separación de los regulares en los curatos que fueran quedando vacantes. ${ }^{6}$ Para el monarca habían cesado los motivos de la concesión otorgada a los religiosos; debía abrirse paso a los seculares para que pudieran disfrutar de los espacios que les correspondían.

El programa debía aplicarse en los arzobispados de México, Lima y Santa Fe. Para prevenir la resistencia de los religiosos la transferencia sería iniciada en curatos que resultaran menos apreciables. Los seculares suplieron con rapidez a los frailes en bastantes lugares, tanto en zonas apartadas como en la propia capital del virreinato. La secularización de doctrinas desencadenó un importante tránsito de personal en el arzobispado. ${ }^{7}$

En esta época había una serie de condiciones que hacían factible la sustitución de los regulares por los seculares. El clero regular era objeto de múltiples críticas por parte de los ilustrados. ${ }^{8}$ Se acusaba a las órdenes religiosas de tener un número excesivo de miembros, así como de tener fuertes problemas de rela-

\footnotetext{
4 José Antonio VILlaseñor, Theatro americano, Descripción general de los Reynos y provincias de la Nueva España y sus jurisdicciones, México, 1746, 29-31.

5 TAYLOR, op. cit. 18.

${ }^{6}$ Real cédula del 4 de octubre de 1749. Archivo General de la Nación de México (en adelante AGNM), Reales Cédulas Originales, vol. 69, exp. 103.

7 TAYLOR, op. cit. 148.

${ }^{8}$ Para ver las críticas al clero regular en España es conveniente revisar: Antonio CORTÉS PEÑA, La política religiosa de Carlos III y las órdenes mendicantes, Granada, 1989, passim.
} 
jación. ${ }^{9}$ Para los regulares la facultad para ocuparse de las doctrinas de indios dependía de la vigencia de una serie de privilegios que estaban siendo desarticulados tanto por la Corona española como por el papado. ${ }^{10} \mathrm{El}$ tiempo de predominio de las doctrinas de los religiosos llegaba a su fin.

En cambio, en términos generales el clero secular era visto con aprobación en los dominios españoles, tanto en la península ibérica, como en América. En Nueva España el virrey Revillagigedo hablaba de que había «muchos individuos doctos» entre los seculares esperanzados en obtener alguna vacante..$^{11}$ Los clérigos tenían una situación favorable para posicionarse en los curatos del arzobispado de México.

Muchos pueblos ya no eran lugares habitados exclusivamente por indios. La población de vecinos españoles, mestizos y mulatos era particularmente visible en las cabeceras, pero también había crecido en un número considerable de pueblos sujetos. A ojos de las autoridades civiles y diocesanas las parroquias eran la institución acorde para dar atención espiritual a feligreses de distinto origen socio racial.

Entre 1750 y 1753, al mismo tiempo que transfería varias doctrinas a clérigos, Manuel Rubio y Salinas realizó visitas pastorales al territorio del arzobispado. El prelado pudo conocer a detalle la situación imperante en diferentes zonas. Obtuvo información útil referente a los lugares administrados por los religiosos: algunos curatos habían sido ocupados de manera interina por las órdenes, otros acababan de quedar vacantes. Pudo detectar doctrinas que sería factible o deseable secularizar en fechas próximas.

En sus visitas el arzobispo vio que había doctrinas muy grandes y prósperas. Aprovechó su presencia en estos lugares para realizar diligencias encaminadas a evaluar la posibilidad de dividir algunos curatos. Por ejemplo, cuando visitó Huichapan y sus pueblos anexos - Cadereyta y Tecozautla - revisó los edificios existentes en las posibles nuevas sedes parroquiales, mandó que fueran levantados inventarios y examinó a varios clérigos. ${ }^{12}$ Pudo contar con elementos para pasar a la acción poco tiempo después.

\footnotetext{
${ }^{9}$ Para la difusión de una imagen negativa del clero regular fue importante la obra de Jorge JUAN y Antonio de UlloA, Noticias secretas de América, Madrid, 1918, passim.

${ }^{10}$ En 1751 el papa Benedicto XIV emitió la bula Cum nuper, la cual era coincidente con uno de los principales argumentos expuestos por la Corona española en la real cédula del 4 de octubre de 1749. La concesión de privilegios a los mendicantes, decía el pontífice, había sido temporal; la medida se había implementado por la escasez de clérigos.

${ }^{11}$ Francisco de Güemes y Horcasitas, Primer Conde de Revillagigedo (1746-1755). «Relación que hace a Agustín de Ahumada y Villalón en 1755», en Instrucciones y memorias de los virreyes novohispanos, México, 1991, 834.

12 Jesús Mendoza MuÑoz, Secularización de la parroquia de Santiago de Querétaro en el siglo XVIII, Cadereyta, 2008, p. 93.
} 


\section{LA CREACIÓN DE NUEVAS PARROQUIAS}

El $1^{\circ}$. de febrero de 1753 Fernando VI emitió una real cédula que intensificaría el ritmo del programa de secularización de doctrinas. Además de que la transferencia proseguiría en los curatos vacantes y en los que estuvieran ocupados sin canónica institución, debía hacerse en todos los lugares donde resultara conveniente la medida. El documento ampliaba también el ámbito de aplicación del programa al conjunto de las diócesis de los dominios españoles en América; en todas, se afirmaba, había «abundante copia de clérigos seculares de suficiente literatura, letradas costumbres y demás dotes necesarios para el ministerio de la cura de almas».13

Rubio empezó a hacer énfasis en la idea de que los regulares debían desocupar los curatos. Hasta ese momento no había encontrado obstáculos para lograr la transferencia de las doctrinas. Los religiosos apenas habían comenzado a articular una respuesta acorde a los alcances de la problemática. ${ }^{14} \mathrm{El}$ prelado expresaba que la salida de los frailes de un mayor número de curatos permitiría cumplir los deseos del rey más prontamente. Además, hacía referencia a un asunto clave: podría establecerse «el numeroso clero de esta diócesis en los curatos, cuya administración les es más peculiar». ${ }^{15}$

En noviembre de 1754 Rubio informaba que había conseguido «apartar»a los franciscanos de siete doctrinas, a los agustinos de seis y los dominicos de cuatro. En estos 17 curatos no habían muerto ni renunciado sus poseedores. ${ }^{16}$ Es importante subrayar que era el prelado diocesano quien tomaba la decisión de qué curatos secularizar y dividir. El virrey Revillagigedo emitía los decretos necesarios, pero lo hacía en los términos que se le solicitaban. ${ }^{17} \mathrm{La}$ buena armonía entre la autoridad eclesiástica y la civil permitió que en esta etapa las transferencias y la división de curatos avanzaran a pesar de algunas protestas y críticas.

\footnotetext{
${ }^{13}$ Real cedula del $1^{\circ}$. de febrero de 1753. AGNM, Reales Cédulas Originales, vol., 73, exp. 13, f. 35 .

14 Véase Ma. Teresa Álvarez ICAZA L., «La puesta en marcha del programa de secularización de doctrinas en el arzobispado de México: impulsos y resistencias (1750-1758)», en Tradición y reforma en la Iglesia hispanoamericana y peninsular, 1760-1830 (en prensa).

15 «Libro de representaciones hechas a Su Majestad sobre doctrinas de regulares», Archivo Histórico del Arzobispado de México (en adelante AHAM), caja 104, libro 3, imagen escaneada (en adelante i.e.) 73-75.

${ }^{16}$ El listado puede verse en Biblioteca Nacional de Antropología e Historia, Fondo Franciscano, vol 139 , f. 337 v.

17 «Oficio del Conde de Revillagigedo sobre secularización de curatos y separar de ellos a los regulares», octubre 1755, en Instrucciones y memorias de los virreyes novohispanos, México, 1991, p. 846.
} 
El arzobispo señalaba que había tomado la decisión de secularizar simultáneamente este conjunto de doctrinas «en resulta del crecido número de opositores que han quedado en el último concurso sin destino». ${ }^{18}$ Señaló que algunos de estos curatos eran «muy dilatados y pingües», por esta razón, argumentó, los proveería «con la calidad de división». Informó que estaba por salir a hacer la visita de la diócesis «y al regreso a la capital estarán hechas las nuevas erecciones». ${ }^{19}$

Esto deja claro que el arzobispo pensaba encargarse personalmente de instrumentar las medidas necesarias para concretar la creación de las nuevas parroquias. Rubio hablaba de que continuaría ocupándose del asunto «hasta que se establezca el numeroso clero de esta diócesis en los curatos»..$^{20}$

En la arquidiócesis de México la coyuntura de la secularización fue aprovechada para lograr una recomposición de la geografía parroquial. ${ }^{21}$ Como varias de las anteriores doctrinas mendicantes habían preservado un amplio territorio, una vez secularizadas era factible dividirlas en parroquias menores. Una de las razones principales para la creación de las nuevas sedes parroquiales era la existencia de una gran cantidad de clérigos necesitados de acomodo. Entre 1700 y 1750 un número creciente de jóvenes habían optado por ingresar al clero secular en el arzobispado de México. En este periodo se habían incrementado las opciones para la formación de sacerdotes; a las instituciones ya existentes, la Universidad y los colegios jesuitas, se había sumado el Seminario Conciliar. $^{22}$

Desde la gestión del arzobispo Lanciego en la sede mexicana habían sido nombrados muchos vicarios, confesores y predicadores con la doble intención de crear plazas para los eclesiásticos y mejorar la atención espiritual de los fieles. Sin embargo, muchos clérigos aspiraban a alcanzar una posición más estable y mejor remunerada. ${ }^{23} \mathrm{El}$ establecimiento de nuevos curatos creó mayores

18 «Libro de representaciones...», AHAM, caja 104, libro 3, i. e. 80.

${ }^{19}$ Ibidem, i. e. 78.

20 Ibidem, i.e. 79.

${ }^{21}$ Óscar Mazín planteó que en este asunto hubo un proceso distinto en cada diócesis. En México y Puebla estuvieron asociados la transferencia de curatos y la creación de nuevas doctrinas, en cambio en Michoacán el obispo Pedro Anselmo Sánchez de Tagle secularizó las doctrinas, pero no hizo una división de los curatos. Véase Óscar Mazín, «Reorganización del clero secular novohispano en la segunda mitad del siglo XVIII», Relaciones 39 (1989), 69-86.

22 Desde los primeros años del siglo XVIII se había incrementado el número de seminaristas. Especialmente durante la gestión de Vizarrón hubo una elevación del nivel espiritual e intelectual y un mejoramiento del orden administrativo, como resultado se dio un incremento del número de ordenaciones sacerdotales. Eduardo Chávez SÁnchez, Historia del Seminario Conciliar de México, México, 1996, 241.

${ }^{23}$ Rodolfo AguirRe SALVAdor, «La secularización de doctrinas en el arzobispado: realidades indianas y razones políticas, 1700-1749», Hispania Sacra 122 (2008), 494.

Hispania Sacra, LXIII

128, julio-diciembre 2011, 501-518, ISSN: 0018-215-X 
oportunidades de empleo para los miembros del clero secular del arzobispado. Las parroquias recién establecidas podían ofrecer ingresos seguros a los curas a cargo de ellas; asimismo, diversos eclesiásticos realizaban tareas auxiliares y recibían retribución por ello.

Un elemento determinante para que los seculares estuvieran en condiciones de hacerse cargo de los curatos fue el conocimiento del idioma de los indios. La información recabada por el arzobispo en sus visitas dejaba en claro que en muchos lugares seguía habiendo una importante población de hablantes de náhuatl y de otomí. Los clérigos del arzobispado que manejaban esas lenguas, y algunas otras, eran abundantes. ${ }^{24}$

Es posible, incluso, que la transferencia de los curatos a clérigos acelerara el reclutamiento de indios en el clero mexicano. ${ }^{25}$ Contar con clérigos que conocieran la lengua facilitó a las autoridades diocesanas las gestiones de secularización y división de curatos. El arzobispo había nombrado algunos vicarios de idioma «para los indios que todavía no estén muy perfectos en la lengua española».;26 algunos eventualmente pudieron llegar a obtener la titularidad de su curato. ${ }^{27}$

Al lograr una mejor organización territorial la autoridad episcopal salía favorecida: ${ }^{28}$ Una de las metas fundamentales de la transferencia de doctrinas a clérigos era que el conjunto de los curas estuviera directamente bajo la autoridad del obispo. Esto, a su vez, le permitiría a la Corona ejercer mecanismos más eficaces de control sobre la Iglesia. Con la existencia de más parroquias el arzobispo de México pudo contar con ministros en mayor número de lugares, lo cual facilitaba la mejor ejecución de sus instrucciones. Manuel Rubio y Salinas estuvo muy pendiente del desempeño de los curas recién nombrados e insistió en la necesidad de que tuvieran una conducta ejemplar. Estuvo particularmente interesado en el tema de los cobros realizados por los nuevos ministros; asimismo, atendió asuntos que impactaban las finanzas de la mitra.

24 Rodolfo AgUiRRe SALVADOR, «Formación y ordenación de clérigos ante la normativa conciliar. El caso del arzobispado de México, 1712-1748», Los concilios provinciales en Nueva España. Reflexiones e influencias, México, 2005, 337-362.

25 David Brading, Una Iglesia asediada, México, 1994, p. 83. Sobre este tema puede verse el trabajo de Margarita Menegus y Rodolfo Aguirre, Los indios, el sacerdocio y la Universidad en Nueva España. Siglos XVI-XVIII, México, 2006, 308 pp.

26 «Libro de representaciones...», AHAM, caja 104, libro 3, i.e. 107.

${ }^{27}$ Ese fue, por ejemplo, el caso de Pedro de Cueto, ordenado a título de idioma otomí. En 1755 era vicario del curato de Zinacantepec; para 1768 era el párroco y juez eclesiástico de ese curato. «Diligencias para la división de Zinacantepec y la erección de Amanalco» AGNM, Bienes Nacionales, leg. 450, exp. 38 .

${ }^{28}$ Castañeda y Marchena explican las distintas razones por las cuales el siglo XVIII fue el «momento cumbre» del episcopado americano. Paulino CASTAÑEDa y Juan MARCHENA, La jerarquía de la Iglesia en Indias: el episcopado americano. 1500-1850, Madrid, 1992, passim. 
La existencia de mayor número de parroquias hacía más expedita la resolución de diversos trámites y conflictos. En su calidad de jueces eclesiásticos, los párrocos eran los ejecutores de los autos y decretos del ordinario; se ocupaban de tareas importantes: atendían causas civiles y criminales leves entre los indios, se hacían cargo de dar licencias para los matrimonios y supervisaban varios asuntos referentes a las cofradías. En el arzobispado la figura del juez eclesiástico se había ido extendiendo previamente a la secularización de doctrinas. ${ }^{29} \mathrm{Sin}$ embargo, el proceso de transferencia y creación de nuevos curatos permitió reforzar la estructura de justicia eclesiástica a nivel local.

En la argumentación para la erección de nuevas parroquias eran mencionadas las ventajas del aumento del número de parroquias para los feligreses. Los vecinos de los pueblos elegidos como sedes parroquiales podían contar con servicios espirituales más prontos y eficaces; los curas podían administrarles los sacramentos y decirles misa con mayor frecuencia. Los fieles no descuidaban trabajo ni familia para acceder a la atención religiosa. Rubio expresó en diversas ocasiones su preocupación por la dispersión que prevalecía entre los indios del arzobispado. ${ }^{30}$ Con la creación de nuevos curatos, incluso los habitantes de pueblos pequeños podían estar más cerca de un ministro. El arzobispo señalaba que los fieles podrían tener «más pronto alivio» en sus necesidades.

La creación de parroquias a mediados del siglo XVIII era una necesidad derivada del crecimiento demográfico. Había pueblos sujetos que tenían una población muy numerosa, lo cual traía consigo la exigencia de contar con un cura. Muchas veces los vecinos de estos pueblos insistían en la erección de las nuevas parroquias. Lograr la autonomía implicaba tener mayor margen de acción para cuestiones políticas y económicas. Los pueblos que adquirían la categoría de cabecera contaban con un gobierno propio y tenían mejores posibilidades de control de sus tierras y de acceso al mercado.

Sin embargo, para los fieles la existencia de nuevos curatos podía generar situaciones desfavorables. Algunos pueblos, acostumbrados a la presencia esporádica de los eclesiásticos, debían habituarse a una vigilancia más rigurosa. Sus acciones podían ser seguidas más de cerca por los eclesiásticos del curato. Había posibilidad de detectar con mayor facilidad las inasistencias a la misa y a la doctrina, la falta de cumplimiento en los sacramentos y otras infracciones. La

\footnotetext{
${ }^{29}$ Rodolfo Aguirre analiza la evolución de la figura del juez eclesiástico en el arzobispado de México. Véase Rodolfo AguirRe SALVAdoR, «El establecimiento de jueces eclesiásticos en las doctrinas de indios. El arzobispado de México en la primera mitad del siglo XVIII», Historia crítica 36, 2008, 14-35.

30 «Relación Ad limina enviada por el ilmo sr. D. Manuel Rubio y Salinas arzobispo de México el 20 de junio de 1767», en Mariano Cuevas, Historia de la Iglesia en México, vol. IV, México, 2003, 100 .
} 
presencia del cura podía conllevar la aplicación de medidas correctivas e incluso de castigos. Los ministros gozaban de mejores condiciones para vigilar los pagos de los feligreses y podían mantener bajo mayor fiscalización a instancias que hasta entonces habían gozado de bastante libertad, como las cofradías.

Para la división de los curatos debía seguirse un procedimiento cuidadoso. El prelado diocesano llegaba al pueblo sujeto a evaluación y le encargaba al juez eclesiástico local que hiciera una serie de averiguaciones. El punto de partida debía ser la pertinencia de la división. El juez debía hacer padrones de la feligresía. Este era un asunto crucial porque solamente era factible crear una nueva parroquia en pueblos con un número considerable de habitantes. Asimismo, debían establecerse las distancias entre la cabecera y los distintos pueblos del curato. Si un pueblo estaba muy cerca de la cabecera lo más aconsejable era que fuera administrado desde allí. El juez debía detectar, o confirmar, la existencia de pueblos importantes que pudieran ser sedes parroquiales, ubicados a una distancia que hiciera recomendable su separación; asimismo, debía sugerir cuáles pueblos sujetos debían quedar incluidos en los curatos proyectados.

Una parte básica de las indagaciones era valorar las posibilidades de funcionamiento de un nuevo curato. El juez debía saber cuáles eran los recursos financieros disponibles. Debía calcular la congrua que quedaría tanto para el cura del curato original como del recién creado. Este era otro tema crucial para concretar la erección: los nuevos párrocos debían contar con lo suficiente para llevar una vida digna; pero, sin causar perjuicio al cura de la cabecera.

Parte de las averiguaciones tenía que ver con asuntos prácticos. El juez debía señalar cuál era el estado de las casas curales del pueblo designado para confirmar si allí podía residir con decencia el personal del curato. También tenía el encargo de levantar inventarios de los bienes de la iglesia, la sacristía, las cofradías y las hermandades de la futura cabecera y sus posibles pueblos sujetos.

Esto permitía saber si habría condiciones en las nuevas sedes para resguardar la eucaristía y realizar las distintas funciones sacramentales inherentes a la condición de parroquia. Además, dejaba en claro la situación económica del curato. Para llevar a cabo todas las gestiones se requería la colaboración de la autoridad local. Se tomaba en consideración su opinión para la toma de decisiones.

Un caso de división que se planteó y concretó velozmente fue el del curato de Huichapan. En 1755 Rubio propuso erigir las proyectadas dos nuevas sedes parroquiales de Cadereyta y Tecozautla. Ambos pueblos cumplían con los requisitos básicos: contaban con una considerable población y suficientes recursos para sostener a un ministro propio. Los feligreses dejarían de recorrer distancias inconvenientes para resolver sus necesidades espirituales. 
El arzobispo comentaba que para concretar la división solamente faltaba el consentimiento del vicepatrono, si bien no dudaba en obtenerlo por la conveniencia del asunto. En el documento que dirigió a Revillagigedo, habló de la utilidad de la erección de las parroquias de Tecozautla y Cadereyta por el numeroso vecindario, las distancias, la suficiencia de congrua para la manutención de los ministros y la insistencia de los vecinos. Con los mismos fines, escribió una carta al fiscal de la Real Audiencia de México. El arzobispo sabía que el virrey remitiría el asunto a su inspección y buscaba ganar tiempo. Señalaba la urgencia de recibir una pronta respuesta «para ocurrir al alivio de mis súbditos». ${ }^{31}$ Seguramente todas las partes estuvieron de acuerdo porque la creación de los dos nuevos curatos se concretó.

El caso de Zinacantepec pareció semejante al anterior al principio, pero tuvo un desarrollo distinto. Manuel Rubio y Salinas comisionó a don Cayetano de Sotomayor, cura y juez eclesiástico del partido de Metepec, para que averiguara si era útil y necesario erigir una nueva parroquia en Amanalco. ${ }^{32}$ Las conclusiones del comisionado parecían no dejar lugar a dudas respecto a la utilidad de la nueva parroquia. Sotomayor señalaba las dificultades que un solo cura tenía para recorrer un territorio amplio y con malos caminos; según especificaba el juez, había una distancia de nueve leguas entre Amanalco y Zinacantepec. Asimismo, los vecinos de Amanalco deseaban separarse de su cabecera y constituirse en parroquia.

Sin embargo, en opinión del juez, no había urgencia en hacer la división; los habitantes de Amanalco contaban con un vicario que les daba misa y socorro espiritual. ${ }^{33}$ Según Sotomayor había una serie de obstáculos para que se erigiera una sede parroquial en ese pueblo sujeto. La iglesia no contaba «con la decencia necesaria» para colocar el Divinísimo, no tenía un techo adecuado ni ornamentos suficientes. Además, decía, el vecindario estaba conformado únicamente por indios; éstos, eran descritos como propensos a la insolencia y la embriaguez. Para el juez únicamente la gente de razón podía custodiar el sacramento. Rubio aconsejaba que los indios incrementaran «la unión y mezcla» con los españoles; resurgía la idea de que los indios necesitaban del ejemplo de aquéllos para mantener una buena conducta. ${ }^{34}$

Diversas personas consultadas por el juez preveían falta de disposición de los vecinos de Amanalco para ocuparse de las reparaciones. Por su pobreza, los

\footnotetext{
31 «Visita pastoral de Manuel Rubio y Salinas (1754-1758)», AHAM, caja 22, CL 1.

32 «Diligencias para la división de Zinacantepec y la erección de Amanalco» AGNM, Bienes Nacionales, leg. 450, exp. 38, 54 fs.

${ }^{33}$ El vicario de Amanalco, el licenciado José Cortés, se había ordenado a título de idioma otomí.

${ }^{34}$ Magnus Mórner, La Corona española y los foráneos en los pueblos de indios de América, Estocolmo, 1970, 342 .
} 
indios tendrían dificultades aun para sufragar los costos de aceite de la lámpara que debería arder en la nueva parroquia; hasta entonces esos gastos habían sido costeados por el cura de Zinacantepec. Para el teniente de alcalde mayor era más apropiado que en Amanalco residiera un vicario porque éste gastaría menos. También el cura de Zinacantepec vio inconvenientes al asunto porque se quedaría sin los ingresos procedentes de Amanalco. Por todos estos elementos fue tomada la decisión de suspender por lo pronto la división del curato de Zinacantepec. 35

A partir de 1755 hubo algunos señalamientos de la autoridad civil expresando dudas acerca de si los clérigos podrían cumplir bien con sus funciones. Al salir de la Nueva España, Revillagigedo señalaba que no había suficientes clérigos versados en los idiomas de los indios. ${ }^{36}$ También los miembros del Ayuntamiento de México habían afirmado que había pocos clérigos titulados por idioma. ${ }^{37}$

La Corona hizo suya esta preocupación, por ello optó por secularizar los curatos sólo si se habían conferido en forma irregular o quedaban vacantes. Rubio manifestó su desacuerdo con esta afirmación; señaló que incluso le sobraban clérigos calificados para llenar todas las doctrinas que aún tenían los regulares. Según él, había en el arzobispado más de 100 sujetos beneméritos sin destino, entre ellos muchos ordenados a título de idioma. ${ }^{38}$

Manuel Rubio y Salinas sabía que las lenguas indígenas estaban en pleno uso en el territorio de la sede mexicana, pero no era una situación que le pareciera conveniente. A partir de 1754 estaba impulsando una campaña para lograr la castellanización de los indios del arzobispado. ${ }^{39}$ Con ese fin había ordenado la erección de escuelas en los pueblos de indios, tanto en las cabeceras como en los demás pueblos que pudieran mantener a un maestro. En opinión del prelado si los indios hablaban la lengua castellana podrían beneficiarse porque conseguirían ennoblecer sus espíritus y salir de la pobreza y desnudez. Expre-

\footnotetext{
${ }^{35}$ En 1768 el arzobispo Francisco Antonio de Lorenzana retomaría el asunto. A su juicio se habían subsanado los inconvenientes detectados en el intento previo, por ello efectuó la erección de una nueva parroquia en Amanalco. «Diligencias para la división de Zinacantepec...» AGNM, Bienes Nacionales, leg. 450 , exp. 38,54 fs.

36 «Francisco de Güemes y Horcasitas...», en Instrucciones y memorias... 831.

37 «Representación hecha por el exmo cabildo de la ciudad de México a SM sobre los graves inconvenientes que resultaban a todo el común de la quita de curatos a los frailes», 1753, Biblioteca Nacional de México (en adelante BNM), Archivo Franciscano, caja127, exp. 1646, doc. 12.

38 «Libro de representaciones...», AHAM, caja 104, libro 3, i. e. 90 . El mismo Rubio había instituido en el Seminario Conciliar una cátedra de idioma mexicano.

39 Tanck señala que fue coincidente el establecimiento de escuelas con la aceleración del programa de secularización de doctrinas Dorothy TANCK, Pueblos de indios y educación en el México colonial, México, 1999, p. 161.
} 
saba incluso sus esperanzas de que en pocos años los indios del arzobispado ya no hablaran otra lengua que el castellano. ${ }^{40}$

Pese a los argumentos del arzobispo, la Corona decidió aminorar la velocidad del programa de secularización de doctrinas. El 23 junio de 1757 fue emitida una real cédula que establecía que no debía transferirse ningún curato hasta quedar vacante. Antes de proceder a la secularización debía revisarse si era conveniente nombrar clérigos, para lo cual debía conocerse si los curas diocesanos sabían los idiomas de los indios o ellos el castellano. Además, fue establecido que las provincias de las diferentes órdenes religiosas conservaran una o dos doctrinas de las más prósperas por cada diócesis. ${ }^{41}$

Rubio manifestó su inconformidad por las nuevas medidas. En su opinión no era necesaria la asignación de las doctrinas a los religiosos. ${ }^{42}$ Sin embargo, a partir de este año fue visible una disminución de la velocidad de la transferencia de curatos. Asimismo, aminoró la insistencia en la castellanización de los indios. ${ }^{43}$

En 1759 fue secularizada la doctrina de Jilotepec. El pueblo de Acambay fue separado de esa cabecera y designado nueva sede parroquial. En este caso se presentaron conflictos. ${ }^{44}$ Los indios de los pueblos sujetos del nuevo curato se habían comprometido con el párroco, Julián Trujillo, a pagarle una contribución de medio real cuando fuera de visita. Cuando el cura tomó colación canónica, halló «tal resistencia en los feligreses» para cumplir lo determinado en el auto de la nueva erección que le fue preciso acudir al encargado de la justicia local. Trujillo también había establecido un pago especial por las fiestas principales. Además, había decidió hacer varias innovaciones como convocar a los niños a la cabecera para participar en procesiones todos los sábados.

Según el cura de Acambay, era preciso apremiar a los indios para que mostraran respeto a su párroco y le entregaran los derechos parroquiales establecidos. Pedía que se reconviniera a los indios fiscales de los pueblos y capitanes de las rancherías y se aclarara cuánto adeudaban. Los indios, instados por el gobernador de Jilotepec, Tiburcio García, respondieron que aceptaban pagar únicamente según arancel y rechazaron hacer otras contribuciones.

\footnotetext{
40 «Libro de representaciones...», AHAM, caja 104, libro 3, i. e. 114.

${ }^{41}$ Real cédula del 23 de junio de 1757, AGNM, Reales Cédulas Originales, vol. 77, exp. 77, fs. 186-191.

42 «Libro de representaciones...», AHAM, caja 104, libro 3, i.e. 158.

${ }^{43}$ Dorothy TANCK, op. cit. 166.

44 «Autos que sigue el bachiller Don Joaquín Trujillo, cura y juez eclesiástico del partido de San Miguel Acambay con los naturales de aquella diócesis sobre que le paguen estos lo que le deben de obvenciones» AGNM, Bienes Nacionales, leg. 156, exp. 7, f. 207-275.
} 
El mismo Rubio y Salinas había promovido el pago por arancel en las parroquias creadas a partir de la secularización. El prelado se proponía lograr un funcionamiento más homogéneo de los curatos del arzobispado, así como evitar enfrentamientos entre los ministros y los feligreses. En muchas ocasiones los indios juzgaron que el pago por arancel los libraba de exigencias abusivas por parte de los curas. Sin embargo, había margen para acuerdos entre las partes. A veces los arreglos funcionaron, pero en otras ocasiones se convirtieron en nuevas fuentes de enfrentamiento.

Trujillo no había encontrado Acambay en condiciones idóneas para funcionar como parroquia. Había tenido que componer la iglesia y la casa cural, así como sufragar el gasto de dos colaterales, campanas y ornamentos. Asimismo, le pagaba de su bolsillo al maestro. Esos gastos, sumados a la dificultad para cobrar las obvenciones esperadas, habían colocado al cura en la incómoda situación de estar endeudado con sus vicarios por una considerable cantidad de dinero. En general los curas debían garantizar el buen estado de la iglesia, así como el adecuado funcionamiento de la parroquia. Sin embargo, los gastos debían estar en proporción con los ingresos. En este pueblo había una situación de desequilibrio: el cura se sentía a disgusto con el incumplimiento de sus feligreses; a su vez los habitantes del curato se sentían presionados en exceso por las exigencias del nuevo cura.

El problema tenía muchas aristas. Los indios de San Pedro, uno de los pueblos incluidos en el nuevo curato, se rehusaban a reconocer a Acambay como su cabecera, a pesar de que parecía convenirles porque sólo había una legua de distancia entre ambos pueblos. Se mostraban interesados en seguir dependiendo de Jilotepec, aun cuando estaba a ocho leguas. Los de San Pedro se negaban a obedecer al gobernador de Acambay, en contraste mantenían «una estrecha alianza y amistad» con el gobernador de Jilotepec a quien continuaban sembrándole cuatro fanegas. No sabemos a detalle las razones de los vecinos de San Pedro para seguir dispuestos a trabajar para un gobernador que ya no era el suyo. Algo queda claro: las decisiones tomadas por el prelado diocesano respecto a la erección de nuevas cabeceras no siempre eran aceptadas por todos los afectados.

Trujillo se dolía de que los feligreses de San Pedro se resistieran a aceptar su autoridad: «no querían confesarse, ni oír misa, que a sus hijos no los enviaban a la doctrina, que las criaturas las llevaban a bautizar a otros curatos...» Incluso, habían pagado la misa de su fiesta patronal en Jilotepec. Es importante subrayar que estos indios no se negaban a cumplir sus obligaciones como cristianos, pero sí a realizar esas actividades en su nuevo curato. Llama la atención la lealtad a su antigua cabecera cuando por la menor distancia les resultaría más cómodo atender sus asuntos espirituales en Acambay. 
La razón de esto podría estar en una disputa personal de los habitantes de San Pedro con el cura de Acambay. Trujillo afirmaba que, en sus feligreses indios, advertía «mayor relajación de vida y costumbres». Seguramente había llegado a esa conclusión a partir de seguir muy de cerca sus pasos. Los indios debieron sentirse agraviados por la vigilancia ejercida por el eclesiástico. El cura, por su parte, debió pensar en medidas para corregir la situación; para ponerlas en marcha, necesitaba de la colaboración del personal indígena del curato. En este punto se le presentó otro problema: por presiones del gobernador de Jilotepec no eran obedecidos sus fiscales.

El conflicto se puso aún peor. Los indios de San Pedro se quejaron del cura de Acambay. Lo acusaban de que les enseñaba «nueva doctrina». Trujillo se defendió: ante un juez comisario hizo rezar a varios indios la doctrina para comprobar que era «la que todo fiel cristiano debe saber». Luego pasó al contraataque: puso a prueba al capitán de San Pedro y a otros indios que habían rehusado confesarse, como no supieron la doctrina los mandó azotar y encerrar en el capítulo. ${ }^{45}$

Según el cura esas medidas eran válidas para obligar a los fieles reacios al cumplimiento de sus obligaciones y funcionaban también para apartarlos de la embriaguez e incontinencia. En respuesta a estas acciones los indios se atumultuaron contra el cura; debieron defenderlo los vecinos de razón. Trujillo remitió a los indios alborotadores a Jilotepec. Sin embargo, no contó con el auxilio del encargado de la justicia civil; por ello, decía, los indios estaban cada vez más «inobedientes e insolentados».

El cura de Acambay denunció que el gobernador de Jilotepec le había escrito una carta «muy insultante»; no le reconocía «las facultades de párroco» y lo amenazaba con agregar a los indios de San Pedro a otra parte. Trujillo había puesto una denuncia contra el gobernador de Jilotepec. Sostenía que, por los «diabólicos influjos» de Tiburcio García, los indios de San Pedro no cumplían con las obligaciones de cristianos ni lo obedecían. No conozco cómo acabó el asunto. Debe haber sido una tarea difícil lograr condiciones de tranquilidad en el nuevo curato.

El asunto ocurrido en Acambay se ubica en un contexto de aumento de los enfrentamientos entre curas y feligreses. Justamente en las décadas de 1750 y 1760 en la arquidiócesis de México predominaron los conflictos por aranceles; como los curas de este territorio dependieron más para su manutención de los derechos pagados por los feligreses se presentaron frecuentes disputas. Otro escenario de tensiones en este periodo se dio entre las cabeceras y los sujetos. ${ }^{46}$

${ }^{45}$ Ese era el nombre que se le daba a un cuarto donde los curas encerraban a los indios si cometían faltas como no saber la doctrina o estar ebrios.

${ }^{46} \mathrm{~W}$. TAYLOR, op. cit. 34. 
En mi opinión habría que incluir en la explicación del fenómeno del incremento de los choques entre feligreses y ministros tanto la secularización de curatos como el proceso de creación de nuevas parroquias.

En 1764 se planteó la posibilidad de separación de Temamatla respecto de su cabecera Tlalmanalco. El caso presentó rasgos singulares porque fue propuesta por el fraile franciscano guardián de Temamatla, Ignacio Saldaña. ${ }^{47}$ Los habitantes de Temamatla deseaban la separación porque se les facilitarían diversas gestiones. Argumentaban la abundancia de vecinos y «suficientísimas tierras». Un elemento importante era la existencia de una «magnífica iglesia sobradamente adornada». Los vecinos de este pueblo sujeto pedían licencia para tener su propio gobernador; lo cual, decían, redundaría en un aumento del pago de tributos.

El virrey Cruillas mandó a hacer averiguaciones con el alcalde mayor acerca de la conveniencia del asunto. El alcalde opinó a favor de la división de la doctrina. También le fue solicitado su parecer al doctrinero de Tlalmanalco, fray Francisco Javier de Contreras. El fraile se opuso a la separación y expresó preocupación por la falta de obediencia de sus feligreses; incluso manifestó su temor de que acabaran pidiendo curas diocesanos. Fray Ignacio insistió en la erección de un nuevo curato. Las autoridades franciscanas le llamaron la atención y le pidieron no generar más inquietud.

Seguramente tenían presente la posibilidad de que los desórdenes llegaran a oídos de las autoridades diocesanas y eso precipitara la secularización del curato. Es muy posible que fray Ignacio aspirara a ocupar una mejor posición, pero tuvo que plegarse a las indicaciones de sus superiores. Por el momento Temamatla siguió dependiendo de Tlalmanalco. ${ }^{48}$

Hacia el periodo final de la prelacía de Manuel Rubio y Salinas todavía ocurrió un evento importante para la reorganización del territorio del arzobispado. No todo se resolvía con la creación de nuevas parroquias. El 18 de octubre de 1764 fue emitida una real cédula para que fueran nombrados tenientes de cura en los pueblos que estuvieran a mayor distancia de cuatro leguas de su cabecera. Muchos curatos de América eran muy extensos y llegaban a incluir pueblos que estaban a grandes distancias del lugar de residencia del cura. Los fieles en tal situación carecían «de todo pasto espiritual» en casos de emergencia. Para resolver esto los curas titulares deberían contar con los auxiliares necesarios;

47 «Determinaciones de NRP Leyza sobre la pretendida división que de la cabecera del curato de Tlalmanalco pretendió la cabilosidad de los indios de Temamatla alentados o movidos por el P. fray Ignacio Saldaña». BNM, Archivo franciscano, caja 110, exp. 1508, doc. 14.

${ }^{48}$ En 1768 fue secularizado Tlalmanalco por instrucciones de Lorenzana. En Temamatla quedó un vicario. AGNM, Bienes nacionales, leg. 603, exp. 2. En 1777 Temamatla ya era un curato. Ernest SÁNCHEZ SANTIRó, Padrón del arzobispado de 1777, México, 2003, 152 pp. 
debían pagarles una cantidad acorde a los ingresos del curato y al alivio del trabajo que les resultara.

La medida anterior era un complemento necesario a la creación de parroquias. No en todos los lugares convenía erigir nuevas sedes parroquiales; sin embargo, debía lograrse un mejor funcionamiento de los curatos existentes. El nombramiento de más clérigos podría considerarse como una respuesta a algunas críticas dirigidas a los seculares. Los religiosos habían señalado que los clérigos contaban con pocos operarios en sus curatos, lo cual era señalado como un impedimento para que atendieran a los fieles como era debido.

$\mathrm{Al}$ mismo tiempo, puede verse como un asunto impulsado por las autoridades para hacer más eficiente la administración parroquial. La argumentación podía ser común a la presentada para la división de curatos: se creaban más fuentes de empleo para los clérigos y se ponía al alcance de los feligreses de pueblos alejados mejores servicios espirituales.

En 1766 cuando el arzobispo Francisco Antonio de Lorenzana inició su gestión, en la sede mexicana había 203 curatos. ${ }^{49}$ Teniendo en consideración que en 1746 José Antonio Villaseñor señaló la existencia de 192 curatos, podemos constatar un incremento significativo: en el transcurso de 20 años fueron creados 11 nuevos curatos. Este avance en la actualización de la estructura administrativa eclesiástica del arzobispado fue posible por la confluencia de diversas condiciones: los esfuerzos del arzobispo Manuel Rubio y Salinas, las iniciativas de la Corona española y la disposición de los actores involucrados en cada caso. Paulatinamente iban creándose condiciones en el arzobispado para lograr mejores mecanismos de control tanto sobre el clero como sobre la feligresía.

\section{CONSIDERACIONES FINALES}

El desarrollo del clero secular en la Nueva España es un tema que necesitamos conocer con mayor profundidad. En el caso específico del arzobispado de México aún tenemos pendientes considerables para estar en condiciones de visualizar con claridad el camino que llevó a este sector del clero a ocupar el lugar hegemónico en la administración espiritual de los fieles. Los clérigos empezaron a ganar terreno desde el siglo XVI; sin embargo, la secularización de doctrinas realizada a partir de 1750 constituyó un hito determinante en este proceso. Hacia fines del siglo XVIII los prelados diocesanos habían nombrado curas seculares en todo el territorio de la arquidiócesis, con la única excep-

\footnotetext{
${ }^{49}$ Había 193 curatos rurales y 10 en la ciudad de México. Véase el listado en Luisa ZAHINo PeÑAFORT, Iglesia y sociedad en México, 1765-1800. Tradición, reforma y reacciones, México, 1996, 64-72.

Hispania Sacra, LXIII

128, julio-diciembre 2011, 501-518, ISSN: 0018-215-X
} 
ción de las dos doctrinas seleccionadas para ser conservadas por cada orden religiosa.

El argumento central de las distintas reales cédulas emitidas para concretar el cambio de ministros era que la cura de almas le correspondía por derecho a los clérigos. Asimismo, para fundamentar la transferencia se hizo énfasis reiteradamente en la sólida preparación del clero secular y en su buena conducta. La secularización de curatos y su posterior división fueron parte de una serie de medidas destinadas a reformar a la Iglesia americana. La expansión de los seculares coadyuvaba al propósito de mantener un clero más homogéneo y leal al monarca español.

La colaboración del episcopado facilitó a la Corona hispana la puesta en marcha de muchos de los programas proyectados. El arzobispo Manuel Rubio y Salinas se mostró sumamente diligente en la instrumentación de la transferencia de curatos a los seculares: recorrió el territorio del arzobispado, adelantó gestiones, superó obstáculos diversos e incluso manifestó su desacuerdo ante las autoridades reales cuando fueron emitidas medidas favorables a las órdenes religiosas.

Rubio sabía de la existencia de un contingente importante de clérigos en espera de oportunidades, por ello decidió acelerar el proceso de desocupación de los curatos en manos de regulares. Seguramente esa fue una consideración que le ayudó a decidir cuáles curatos secularizar más prontamente con el fin de dividirlos. Para el clero la erección de nuevas parroquias posibilitó el acceso a mejores fuentes de empleo. Esto, a su vez, favoreció que siguiera en aumento el número de clérigos en los años subsecuentes.

Las autoridades reales y el episcopado coincidían en el propósito de fortalecer a la parroquia, era considerada la piedra angular en la organización del territorio de una diócesis. En el arzobispado de México hubo un esfuerzo conjunto de la Corona y los prelados diocesanos para poner al día la estructura parroquial. Para lograr este fin era necesario secularizar las doctrinas y erigir nuevos curatos. Rubio fue el promotor inicial de estos proyectos; los atendió con interés prácticamente a lo largo de toda su gestión. Los dos siguientes arzobispos de México le dieron continuidad a ambos asuntos.

Para crear una sede parroquial no bastaba con cubrir los requisitos básicos: vecindario abundante, distancia considerable a la cabecera, deseos de la feligresía. Debía haber condiciones que hicieran factible el funcionamiento de un nuevo curato. La propuesta para efectuar la división podía venir de diferentes sectores. Prosperaba si había acuerdo de todas las partes involucradas. Si alguna de ellas veía afectados sus intereses podía oponerse. En los casos de Amanalco y Temamatla los reparos procedieron de los ministros que estaban a cargo del curato por dividir. Eso bastó para suspender las gestiones. 
La creación de nuevos curatos posibilitó una interacción más intensa entre la clerecía y la feligresía. El clero pudo hacerse presente en un número mayor de pueblos de indios del arzobispado. Se creaban condiciones para un funcionamiento más eficaz de los curatos. Los sacramentos podían ser administrados con regularidad y las gestiones judiciales resolverse con prontitud. Las actividades cotidianas, como la misa y la doctrina, eran realizadas con mayor comodidad.

En general los pueblos estaban interesados en tener un ministro a su alcance. Sin embargo, el inicio de una nueva administración requería que el párroco y los fieles llegaran a un punto de entendimiento. A los nuevos curas no siempre les fue fácil establecer su autoridad. Era importante que contaran con el apoyo de la justicia local, si no era así, se complicaba conseguir la obediencia de los feligreses. También era un factor necesario la ayuda de un personal indígena eficaz.

La cuestión de la retribución de los curas fue fuente de abundantes conflictos. Rubio estaba consciente de ello e intentó evitarlos, insistiendo en que se establecieran pagos fijos por los servicios religiosos. A pesar de ello, había margen para que los curas pidieran algunas contribuciones especiales. Llegó a presentarse la situación de que los fieles aceptaran inicialmente hacer esos pagos, pero luego se negaran a realizarlos. Las pugnas podían derivarse de una cercanía incómoda. Los curas estaban en condiciones de ejercer una vigilancia que a ojos de los feligreses quizá resultara excesiva. Las cosas llegaban a salirse de control si el ministro se portaba demasiado riguroso o se extralimitaba en la aplicación de castigos.

En el mundo indígena el surgimiento de nuevas unidades políticas y eclesiásticas tenía implicaciones de gran trascendencia. Debía replantearse la lealtad entre cabeceras y sujetos. Era frecuente que los pueblos menores anhelaran funcionar de manera autónoma. Para las nuevas cabeceras se presentaban oportunidades ventajosas, pero, como pudo verse en el caso de los indios de San Pedro, los pueblos que quedaban sujetos a las nuevas sedes no necesariamente juzgaban favorable el cambio; este caso deja en claro que los asuntos de carácter político podían entorpecer el establecimiento de un nuevo curato.

Por último, hay otro elemento a destacar. En la medida que eran creados nuevos curatos, fue realizado un importante esfuerzo para la habilitación de mayor número de iglesias en el territorio de esta demarcación. Para cumplir con las exigencias de una sede parroquial se hicieron importantes obras de reparación y adorno. La erección de nuevas parroquias dejó una huella tangible en los pueblos del arzobispado de México. 